\title{
Mathematical Models for Controlling Wetted Soil Masses Forming under the Practice of Water Added Corn seeding
}

\author{
Y.G. Yang, W. Zhang* \\ College of Mechanical and Electronic Engineering \\ Northwest A\&F University \\ Yangling Shaanxi ,P.R.China \\ *Corresponding author
}

\author{
G. Yang \\ School of Information Science and Engineering,Central \\ South University \\ Changsha Hunan, P.R.China
}

\begin{abstract}
As one China specific practice, the practice of water added seeding is simple, convenient and cheap to adopt and its most important strength is that it is suitable for developing countries to adopt it. In order to increase penetration depth and reduce evaporation of irrigation water with the conventional practice of water added seeding, get rid of white pollution caused by plastic film mulching, and determine the appropriate parameters of wetted soil masses for effective irrigation use efficiency in light of soil conditions and droughts, especially downward depth and horizontal distances of irrigation water infiltration into soil, the authors successfully developed the practice of water added seeding integrating soil clod formation by loosening. Upon the adoption of the practice in soil tillage, soil clods ranging within $10 \sim 20 \mathrm{~mm}$ in size will form and brace against each another to create porous spaces among them , so that irrigation water quickly moved down through porous spaces upon the action of gravity. And in the meantime, when they meet irrigation water, the clods will quickly break up, thereby not affecting seed germination and seedling emergence of corn. The study established the mathematical models for wetted soil masses occurring with the practice of water added seeding and then verified them by experimentation. Where the soil loosening techniques, holing methods, soil water content, horizontal distance and downward depth of added water infiltration required after water adding were obtained, the appropriate added water rate per seeding hole and loosened soil depth could be calculated by adopting the proposed mathematical model. As a result, the study made it feasible to simply and effectively manage the parameters of irrigation water wetted soil spaces, thereby helpful to realize the two targets of drought fighting and water saving that the conventional practice of water added seeding intended to realize.
\end{abstract}

Keywords-water added seeding; soil loosening; controlling wetted soil mass; mathematical model

\section{INTRODUCTION}

China is one of the thirteen countries suffering the most severe shortage of water in the world[1]. However, the arid and semi-arid area of northwest China, which makes up $42 \%$ of the total area of China, only posses $5.84 \%$ of the total water of China. Moreover, the water usage efficiency is only ranging within $0.60 \sim 0.75 \mathrm{~kg} / \mathrm{m}^{3}$, the average irrigation water usage efficiency is 0.43 [2],but the world's highest irrigation water use efficiency up to 0.7 [3].To develop and adopt water-saving and drought-resistant techniques are crucial to the development of modern agriculture of arid and semi-arid area in the world[4],however many of the related technologies have certain disadvantages[5], and they are not suitable for our nation's rural productivity level of development. For example: micro-irrigation, especially drip irrigation[6],is a localized farmland irrigation technique with remarkable water saving effect in modern agriculture. However, its major defect is its high cost investment and easy water blockage[7].While the regulated deficit irrigation studies, from crop physiological point of view[8], is also not be able to cope with the drought issues of all important crop germination and emergence[9].Therefore, if severe drought occurs during the corn seeding period, farmers of many different places will adopt the practice of water added corn seeding [10], i.e., holing $\rightarrow$ pouring water into holes $\rightarrow$ seed placement $\rightarrow$ holefilling, which is capable of wetting soil surrounding corn seeds, thus promoting corn seed germination and corn seedling emergence (for example, the thick line of Figure 1 delimits a wetted soil mass named wetted soil mass 1 ).

However, with this conventional practice of water added seeding method, wetted soil masses are close to soil surface and the horizontal length is around 1.5 2.5 times as much as its vertical depth[11]. Therefore, the water can only penetrate into shallow soil which causes amount of evaporation. If adopting the plastic film to reduce the evaporation, the white pollution is another issue. As a result, the authors first tried to develop a loosening shovel employed practice of water added seeding, i.e., employing soil loosening shovel to loosen seed bed soil and then carrying out water added seeding[12]. However, this method performance is not satisfying. So the authors tried to develop another clod-forming cutter employed practice of water added seeding which employing clodforming cutter to cut seed bed soil to form clods ranging within $10 \sim 20 \mathrm{~mm}$ in size. Those loess clods can be broken up immediately after meeting water thus exerting no influence on corn seed germination. Because the clods braced against each other and large pores is therefore formed among them. As a result, the irrigation water quickly move down through the pores upon the action of gravity so that wetted soil masses formed $13 \mathrm{~mm}$ deeper (Figure 1L); and the height(h) of wetted 
soil masses was $25 \mathrm{~mm}$. The height to width $\operatorname{ratio}\left(\mathrm{S}_{2} / \mathrm{H}_{2}\right)$ of wetted soil masses decreased from 1.3 to $0.8[13]$.

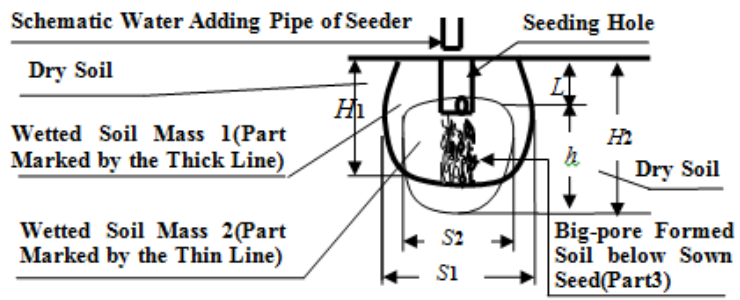

FIGURE I. THE PROFILE OF A WETTED SOIL MASS UNDER THE PRACTICE OF WATER ADDED SEEDING.

The clod-forming cutter employed practice of water added seeding is able to effectively promoting irrigation water to penetrate into deeper soil and reduce its evaporation, however, how to control vertical and horizontal pen nitration distances of irrigation water was the target of the study present in the paper. Where the clod-forming cutter employed practice of water added seeding is adopted, the parameters of wetted soil masses are determined by the soil conditions and droughts. However, they are realized from loosened soil structure, hole size and water addition rate. Consequently, before the water added seeding is done, the parameters of wetted soil masses should be first determined, such as distribution and mass of big pore-formed seed bed soil, structure of seeding hole, water content of original soil and so on. The relationship to the structural parameters for seed bed soil should also be confirmed so that the working parameters of water adding seeders can regulated as required.

\section{MATHEMATICAL MODEL FOR WETTED SOIL MASSES}

\section{A. Formation of Wetted Soil Masses}

Located in Yangling, the experiment land had clay Lü soil, an agricultural soil developing from parent materials of loess. Figure 2 shows how the experiment land was band loosened and where the seeding holes into which water was added distributed on the land. Figure 3 presents the profile of a wetted soil mass forming in a seeding hole location.

Figure 3 presents the profile structures and wetted masses of the loosened and irrigated soil, which showed that loosened soil is composed of two parts, upper loosened soil( delimited by $\mathrm{B}, \mathrm{C}_{1}, \mathrm{C}_{2}$ and $\mathrm{E}$ in the figure 3 ) and lower fine soil( delimited by $C, D, C_{3}$ and $C_{4}$ in the figure 3 ). Upper loosened soil has big pores and the infiltration of added water into soil can be divided into two stages when water added seeding is done. At the first stage, added water moves down through the big pores on the action of gravity. The water washes down fine soil particles resulting from soil loosening towards the bottom of upper loosened soil (delimited by $\mathrm{C}_{1}, \mathrm{C}$, $\mathrm{D}$ and $\mathrm{C}_{2}$ in the figure 3)where the fine soil particles accumulate and finally block the big soil pores. As a result, it prevents added water from further moving downward. And during its infiltration process, added water is partially absorbed by soil clods and partially by fine soil particles (delimited by B, C, D and E in the figure 3). At the second stage, absorbed water at the first stage partially infiltrates into its surrounding area in a regular pattern and partially into soil collapsed while holing and soil backfilled after seed sowing(delimited by A,B,E and F in the figure 3). After the completion of the infiltration process, wetted soil masses of certain shapes (looking like an apple delimited by the thick lines in the figure 3 ) and sizes form surrounding corn seeds, thereby capable of ensuring seed germination.

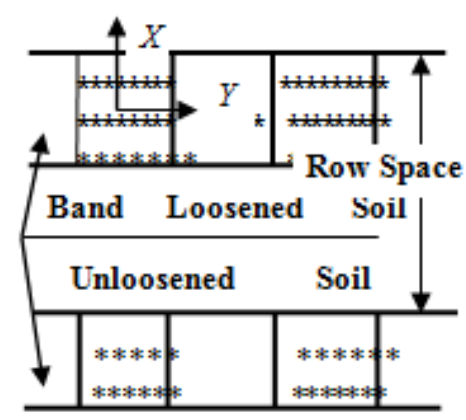

FIGURE II. BAND LOOSENED EXPERIMENT LAND AND THE SEEDING HOLES ON THE LAND.

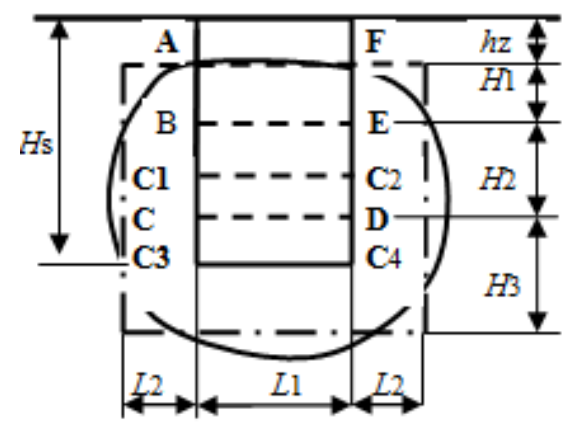

FIGURE III. THE PROFILE OF A WETTED SOIL MASS FORMING IN A SEEDING HOLE LOCATION.

Collapsed soil and backfilled soil exert great influence on water infiltration into soil. Because the infiltration intensity of added water is lower than its water adding intensity, a great proportion of added water infiltrates into collapsed soil and backfilled soil at a low velocity if the traditional practice of added water seeding is adopted. Therefore, the wetted soil masses form close to soil surface (see wetted soil mass 1 delimited by the thick line in Figure1). As a result, a high evaporation of added water occurs. In contrast, with the practice of water added seeding investigated by this paper, there are no standing water seen in the holes after water adding and only a small proportion of added water infiltrating upward into backfilled soil. Therefore the wetted soil masses (see wetted soil mass 2 delimited by the thin line in Figure1) form $h_{z}$ deeper (See Figure 3), which is the fundamental reason why wetted soil masses lies deeper than that of the traditional practice of water added seeding.

\section{B. Mathematical Model Establishment of Wetted Soil Masses}

In order to establish a simple mathematical model to calculate their parameters, wetted soil masses are assumed as quadrangular bodies under the practice of water added seeding according to characteristics of soil loosening and holing showed in Figure 2. 
With the practice of water added seeding adopted, the accumulative infiltration of added water is composed of three parts: (1) water which infiltrates into collapsed soil and backfilled soil; (2) water which infiltrates into clods in upper loosened soil and fine particles in lower fine soil; and (3) water which infiltrates into other soil parts beyond those mentioned previously. Parts of water (1) and (2) are calculated by the following formula (see Figure 3):

$$
Q_{j}=\left(\theta_{3}-\theta_{1}\right)\left(H_{1}+H_{2}\right) L_{1} \frac{\rho_{t}}{\rho_{s}} 10^{-3}
$$

Where, $Q_{J}$ - accumulative infiltration of parts of water (1) and (2) along the direction of $\mathrm{Y}\left(\mathrm{ml} . \mathrm{mm}^{-1}\right) ; \theta_{3}$ - mass-based soil water content after water infiltration into soil $(\%) ; \theta_{1}$ initial soil water content of experiment land $(\%) ; \rho_{\mathrm{t}}-$ soil density or bulk density $\left(\mathrm{g} . \mathrm{mm}^{-3}\right) ; \rho_{\mathrm{s}}$ - water density (g.mm $\left.{ }^{3}\right) ; H_{1}$ - distance from seeding hole bottom to the upper surface of wetted soil mass (mm);

$\mathrm{H}_{2}$-infiltration depth of added water at the first stage $(\mathrm{mm}) ; L_{1}$ - seeding hole diameter $(\mathrm{mm})$.

Practically, $H_{1}$ and $H_{2}$ are difficult to measure and thus $H_{1}+H_{2}$ of formula (1) is transformed as the following according to the geometric relations according to Figure 3:

$$
H_{1}+H_{2}=H_{s} P_{j}-h_{z}
$$

Where, $H_{s}$-loosened soil depth $(\mathrm{mm}) ; h_{\mathrm{z}}$-distance between experiment land surface and upper surface of wetted soil mass $(\mathrm{mm}) ; P_{\mathrm{J}}$-volumetric percentage of soil clods to loosened soil (\%).

In Eq. (2), $h_{z}$ is easy to measure, $H_{s}$ and $P_{J}$ depends on working parameters of soil loosening machine under certain soil conditions. However, even if $H_{s}, P_{J}$ and $h_{z}$ are the same, there still are two more situations under which Eq. (2) cannot be applied: (1) the smaller the soil pore diameters are, the easier to block the soil pores is and the smaller the sum of $H_{l}$ and $H_{2}$ is; (2) different soil loosening modes, such as band loosening (see Figure 2) and full loosening, can make the sum of $H_{1}$ and $H_{2}$ varies. This is because they cause water to face different horizontal infiltration resistances. Therefore, considering that $\mathrm{H}_{1}$ and $\mathrm{H}_{2}$ mainly depend upon the volumetric percentage of soil clods to loosened soil, the coefficient of $k$ is introduced to correct $P_{J}$ and then Eq. (1) can be further expressed as the following:

$$
Q_{j}=\left(\theta_{3}-\theta_{1}\right)\left(H_{s} P_{j} k-h_{z}\right) L_{1} \frac{\rho_{t}}{\rho_{s}} 10^{-3}
$$

After the infiltration of added water at the first stage, water infiltrated into porous spaces among soil structural bodies is influenced very weakly by its gravity and thus its horizontal and downward infiltrations are assumed to be equal, i.e., $H_{3}=$ $L_{2}$ in Figure 3. According to the geometric relationship shown in Figure 3, after water is added, the horizontal length and vertical height of the wetted soil mass can be calculated by the following equations:

$$
L=L_{1}+2 L_{2}=L_{1}+2 H_{3}
$$

Where, $L$ - the horizontal length of wetted soil mass ( $\mathrm{mm})$.

$$
H=H_{1}+H_{2}+H_{3}=\left(H_{s} P_{j} k-h_{z}\right)+H_{3}
$$

Where, $H$-vertical height of wetted soil mass (mm).

The accumulative infiltration of Part (3) of water is calculated by the following formula:

$$
Q_{m}=\left(\theta_{3}-\theta_{1}\right) \frac{\rho_{t}}{\rho_{s}} 10^{-3}\left[2 H_{3}\left(H_{s} P_{j} k-h_{z}\right)+H_{3}\left(L_{1}+2 H_{3}\right)\right]
$$

Where, $Q_{\mathrm{m}}$ - accumulative horizontal infiltration of Part (3) of water $\left(\mathrm{ml} . \mathrm{mm}^{-1}\right)$.

Then, the total horizontal infiltration of added water can be calculated by the following equation:

$$
Q=Q_{j}+Q_{m}
$$

Equations(3-7) is obtained based on the assumption that wetted soil masses are assumed as quadrangular bodies under the practice of water added seeding. However, according to the experimental results, the wetted soil masses look like an apple, appearing slightly larger in their upper parts and vertically longer. The cross-sections perpendicular to ground surface approximately look like the shape of the area delimited by the curve in Figure 3. Therefore, to determine $k$ is crucial to reduce the errors caused by the theoretically calculated length and width of wetted soil masses. The following two steps should be implemented in order to obtain an appropriate value of $k$. Firstly, under specific soil conditions, experiment land is loosened so that different test locations of the land can have different proportions of soil clods. Then water added seeding can be implemented and parameters of wetted soil masses in the different locations, especially their lengths and widths, can be obtained. Secondly, those parameters are employed to determine the correction coefficient of $k$ according to Equations(3-7).

Experimental results involving clay soils show that if the mass percentage of soil clods to loosened soil is above $50 \%$, the correction coefficient of $k$ does not vary significantly. The value of $k$ is approximately equal to 1.3 .

\section{Example and Verification of the Mathematical Model for Wetted Soil Masses}

The experiment method was as follows: firstly, five test plots were randomly chosen on the above-mentioned experiment land and band loosened; secondly, ten seeding holes were dug in soil loosed bands of each plot and the dug up soil from each of the seeding hole was weighed; thirdly, clods $\geqslant 10 \mathrm{~mm}$ were separately isolated from the dugout soils from the different seeding holes and weighed. Then the percentages of their weights to the dug-out soil weights were accordingly calculated. Similarly, another ten seeding holes were dug in the soil loosened bands and water was filled into the holes at the rate of $200 \mathrm{ml}$ per hole. After water was added 
into them, the holes were backfilled with the soil dug up from them immediately. After 20 minutes, the dry soil layers surrounding wetted soil masses formed in the locations of the seeding holes were stripped; then the lengths and widths and calculated their average values. The water contents $\left(\theta_{3}\right)$ of the wetted soil masses were measured at the same time.

The other known conditions are as follows: the initial water content of the experiment land was $\theta_{l}=10 \%$; the loosened soil depth was $H_{s}=150 \mathrm{~mm}$; the soil density of the land was $\rho_{t}=2.7 \times 10^{-3} \mathrm{~g} / \mathrm{mm}^{3}$; the water density was $\rho_{s}=1.0 \times 10^{-}$ ${ }^{3} \mathrm{~g} / \mathrm{mm}^{3}$; the diameters of the seeding holes were $L_{l}=60 \mathrm{~mm}$; the depth difference of the wetted soil masses under the different seeding modes was $h_{z}=13 \mathrm{~mm}$; the correction coefficient was $k=1.3$.

The results calculated by Equations (3-7) and the measured results are shown in Table I. In the table, the coinciding degrees between the calculated and measured wetted soil masses (see Figure 3) were the ratios of the overlapped profile area of the two wetted soil masses to the sum of their overlapped and non-overlapping profile areas.

TABLE I. LENGTHS AND WIDTHS OF THE CALCULATED AND MEASURED WETTED SOIL MASSES.

\begin{tabular}{|c|c|c|c|c|c|c|}
\hline \multicolumn{2}{|l|}{ Test code } & 1 & 2 & 3 & 4 & 5 \\
\hline \multicolumn{2}{|c|}{ Soil clod percentage (\%) } & 54.8 & 59.8 & 55.69 & 51.6 & 61.7 \\
\hline \multicolumn{2}{|c|}{$\begin{array}{l}\text { Soil water content after water adding } \\
\left(\theta_{3} / \%\right)\end{array}$} & 20.3 & 19.5 & 19.8 & 20.0 & 18.7 \\
\hline \multirow{2}{*}{$\begin{array}{l}\text { Estimated Wetted } \\
\text { soil mass }\end{array}$} & Length $(\mathrm{mm})$ & 103.4 & 100.4 & 104.2 & 109.7 & 108 \\
\hline & Width(mm) & 116 & 124.2 & 117.7 & 112.5 & 131 \\
\hline \multirow{2}{*}{$\begin{array}{l}\text { Measured Wetted } \\
\text { soil mass }\end{array}$} & Length(mm) & 113 & 109 & 110 & 112 & 110 \\
\hline & Width(mm) & 118 & 123 & 115 & 117 & 120 \\
\hline \multicolumn{2}{|c|}{$\begin{array}{l}\text { The coinciding degree between the } \\
\text { profiles of the two wetted soil masses } \\
(\%)\end{array}$} & 90 & 91.3 & 92.7 & 94 & 90 \\
\hline
\end{tabular}

\section{CONCLUSION AND DISCUSSION}

1. The calculated and measured results showed that the overlapping degrees of the wetted soil masses were above $90 \%$, thus proving that the developed Equations(3-7) is reliable.

2. The practice of water added seeding investigated in this paper is that soil loosening created soil clods below seed hole bottom and the clods formed big pores among themselves by propping against one another, thus channeling added water to infiltrate. Therefore, the higher $P_{J}$ of Equations(3-7) is, the more controllable the formation of wetted soil masses is. And if the soil loosening method and technique are determined, the value of $P_{J}$ is accordingly determined. The larger value of $P_{J}$ is, the better performance is. The maximum value of $P_{J}$ is close to 1. The correction coefficient $k$ is related to $P_{J}$ and generally equal to or above $1 . k$ will be decreased if $P_{J}$ is increased. In some specific sites, $P_{J}$ and $k$ are needed to be predetermined by experimentation. $h_{z}$ was related to seeding hole depth and $L_{1}$ is depended on holing method. $L, H$ and $\theta_{3}$ are determined by the local soil texture, drought tolerance lasting time after water added seeding and particularly, the water evaporation pattern caused by the climate. Those three parameters need to be satisfied where the practice of water added seeding was adopted. Their realizations are achieved by regulating $Q, H_{s}$ and $H_{3}$. In conclusions, at the case of that soil loosening techniques and holing methods have been decided, the clod percentage of $P_{J}$ and the seeding hole diameter of $L_{1}$ are determined accordingly. As a result, the soil water content, the horizontal distance and downward depth of added water infiltration required after water adding can be calculated by employing Equations(3-7) which estimates the added water rate per seeding hole $Q$ and the loosened soil depth $H_{s}$.

\section{REFERENCES}

[1] Kampeng Lei, Shaoqi Zhoua. Per capita resource consumption and resource carrying capacity: A comparison of the sustainability of 17 mainstream countries. Energy Policy, 42, pp. 603-612, 2012

[2] Ma Junyi, Wang Ying. Drawing Lessons from Israeli Experience in Agriculture Development to Promote Chinese Water-Saving Agriculture. World Agriculture(in Chinese), (6), pp. 31-34, 2010

[3] Wang Zhizhen,Ren Chuandong.Talk about water conservation by irrigation water efficiency.Water Conservancy world (in chinese),11, pp.39-41, 2012

[4] Norwood, Charles A. Water Use and Yield of Limited-Irrigated and Dryland Corn. Soil Science Society of America Journal, 64(1), pp. 365 371,2000

[5] Giulia Vico,Amilcare Porporato. From rainfed agriculture to stressavoidance irrigation: I. A generalized irrigation scheme with stochastic soil moisture. Advances in Water Resources,34(2), pp. 263-271, 2011

[6] Nazirbay Ibragimov, Steven R. Evett, Yusupbek Esanbekov, Bakhtiyor S. Kamilov, Lutfullo Mirzaev, John P.A. Lamers. Water use efficiency of irrigated cotton in Uzbekistan under drip and furrow irrigation. Agricultural Water Management 90(1-2), pp. 112-120, 2007

[7] Li Zongyao.Water-Saving Techniques(in Chinese). Version 2.Beijing: China Waterpower Press, pp. 37-46, 2010

[8] Mustafa Ünlü,, Rıza Kanber, D. Levent Koc, Servet Tekin, Burcak Kapur. Effects of deficit irrigation on the yield and yield components of drip irrigated cotton in a mediterranean environment. Agricultural Water Management, 98(4) ,pp. 597-605, 2011

[9] Sui-Kwong Yau, Musa Nimah, Mohamad Farran. Early sowing and irrigation to increase barley yields and water use efficiency in Mediterranean conditions. Agricultural Water Management, 98(12), pp. 1776-1781, 2011

[10] Mei Xurong.Water Saving Irrigation in China(in Chinese). Beijing: China Agricultural Sci-Tech Press, pp. 136-145, 2006

[11] Li Ziqiang, Guo Chudong, Yang Tianen. Analysis of Soil Moisture Redistribution in Farmland under Bed-Irrigating Sowing. Journal of Anhui Agri. Sci.(in Chinese), 34(1), pp. 108-109, 195, 2006

[12] YangYougang, Xue Shaoping, Yang Qing, et al. Experimental study on 2BSSF-3 type surface tillage and irrigating-sowing machine. Transactions of the Chinese Society of Agricultural Engineering(in Chinese), 24(2), pp.136-139, 2008

[13] Yang Yougang, Zhang Hong, Feng Tao, et al. Topsoil and Subsoil Combined Cultivator and Top-soiling Experiment.Journal of mechanical engineering(in Chinese), 48(19), pp. 163-168, 2012 